\title{
Body size and social dominance influence breeding dispersal in male Pachydiplax longipennis (Odonata) \\ Shannon J. McCauley
}

\begin{abstract}
.
1. Dispersal behaviour can be affected by an individual's phenotype, by the environmental or social context they experience, and by interactions between these factors. Differential dispersal propensities between individuals may also be an important modifier of functional connectivity between populations. To assess how a key trait, body size, affected both social interactions and dispersal behaviour, this study examined the relationship between body size, antagonistic interactions, and breeding dispersal in male dragonflies (Pachydiplax longipennis) across a seasonal decline in adult body size.

2. During a seasonal peak in male body size in this study, dispersers were smaller than non-dispersers. Later in the season, the body size of dispersers and non-dispersers did not differ.

3. Focal observations found that body size was related to competitive dominance, large males engaged in aggressive chases more often and smaller males were more frequently pursued.

4. These results indicate that when large males were present, small males were more likely to disperse suggesting that dispersal is a tactic adopted by social subordinates in this context. If breeding dispersal is typically undertaken by subordinate males, functional connectivity between populations may be less than estimated from absolute dispersal rates.
\end{abstract}

\section{Introduction}

Dispersal, the movement of individuals away from a site of origin, has important consequences for populations, influencing their dynamics, genetic structure, sex ratios, and the phenotypic composition of patch residents (Hanski, 1999; Clobert et al., 2001; Holyoak et al., 2005). Models examining the consequences of dispersal for populations often assume fixed rather than conditional dispersal strategies and do not incorporate variation in individual dispersal behaviour (Bowler \& Benton, 2005). However, there is growing evidence that individuals within a population may differ in their ability or propensity to disperse between habitat patches (Massot \& Clobert, 1995; Massot et al., 2002; Meylan et al., 2002; Dingle, 2006; Benard \& McCauley, 2008; Bonte et al., 2008; Clobert et al., 2009). These differences arise from interactions between the state of the individual (i.e. phenotype or condition), the environmental or social context, and dispersal behaviour. Correlations between dispersal and individual state may arise either incidentally through associations between other behaviours or because the costs and benefits of dispersal are not equivalently experienced by all phenotypes within a population, and consequently individuals adopt different dispersal strategies. Identifying traits associated with alternative dispersal strategies or outcomes can provide insight into the mechanisms underlying dispersal. Additionally, phenotype-dependent dispersal can affect how connectivity develops within landscapes and influence the extent to which dispersers functionally link habitat patches (Benard \& McCauley, 2008). 
The decision to disperse or to remain at a site is expected to be influenced by the environmental and social context that an individual encounters. Interactions among conspecifics may be especially important in determining which individuals engage in breeding dispersal (movement between breeding sites), and which remain resident at a breeding site (Bowler \& Benton, 2005; Clobert et al., 2009). However, relatively few data exist on how traits associated with alternative dispersal behaviours are also related to conspecific interactions and even fewer studies have examined this in a natural landscape context (Clobert et al., 2009). Therefore, integrating data on dispersal, conspecific interactions at the breeding site, and individual level traits can provide novel insights into why individuals disperse and how the social context affects which individuals disperse.

For male dragonflies, the social context experienced is largely shaped by the other males in the population. In territorial odonates such as the focal species in this study, Pachydiplax longipennis (Burmeister, 1839) males guard breeding territories around the periphery of the water body. Male $P$. longipennis spend much of their time perched on vegetation emerging from or surrounding the water body, and engage in aerial chases and battles with other males during disputes over territory (Johnson, 1962; Fried \& May, 1983). Activity at the pond consists mostly of reproductive behaviour as males engage in little feeding near their breeding ponds (Fried \& May, 1983; Baird \& May, 2003). Body size can influence the ability of male odonates to defend breeding territories at ponds (Koenig \& Albano, 1985; Moore, 1990; Fincke, 1992; Sokolovska et al., 2000; Beck \& Pruett-Jones, 2002) although physiological parameters can also play an important role in territorial success (Marden \& Waage, 1990; Marden \& Cobb, 2004). Within territorial odonates, the ability of a male to hold territory is critical to reproductive success (Fincke, 1992; Plaistow \& SivaJothy, 1996; Irusta \& Ara'ujo, 2007). Therefore, male body size can have fitness consequences through its impact on the outcome of antagonistic interactions between males and their ability to maintain a territory. The consequences of male body size and social dominance for territorial success can change the relative value of dispersal for males and may favour dispersal by small, socially subordinate males. However, the importance of body size may also change across a seasonal cline in adult body size. Declines in adult body size across the emergence season are common in insects (Sweeney \& Vannote, 1978; Palmer, 1984; Forrest, 1987; reviewed in Rowe \& Ludwig, 1991) including dragonflies (Corbet, 1999; Fincke \& Hadrys, 2001). This progression may change the competitive context individuals experience at the breeding pond, altering the conditions under which dispersal decisions are made. However, this change has been insufficiently integrated into studies of the relationship between body size and dispersal in odonates. Based on the importance of successfully holding a territory for reproductive success in male dragonflies, this study tested the hypothesis that the effects of body size on male antagonistic interactions and dominance would affect the cost-benefit structure of dispersal for male odonates and result in dispersers being characterized by small body size. However, as body size declined across the season, the expectation was that the role of body size in determining social status would decrease and the magnitude of body size differences between dispersers and non-dispersers would decrease.

A mark-resight approach was used to conduct both focal observations and surveys of multiple ponds for dispersers to test two predictions of this hypothesis. First, that body size would be positively associated with dominance during antagonistic interactions between males. Second, that dispersers would be relatively small males and that dispersal distance and body size would be negatively correlated. The dispersal study was conducted in year 1 of the 
study, across a seasonal decline in body size. Comparisons of resident and dispersing males were made within three distinct time periods to assess the effects of the social context males experience on dispersal behaviour. The relationship between body size and behaviour including male-male interactions was examined in year 2 of the study using focal observations of marked males including both dispersers and non-dispersers.

\section{Materials and methods}

\section{Study system}

Pachydiplax longipennis is a sexually dimorphic, mid-sized (28-45 mm body length, males $>$ females) dragonfly widely distributed across North America (Needham et al., 2000). In this study region (Northern California) the adult flight season extends from mid-June through mid- to late August with new individuals entering the adult population through emergence from the aquatic larval stage between mid-June and the end of July (S. J. McCauley, pers. obs.). The structural elements of body size (i.e. wing length and exoskeletal dimensions but not mass) are fixed at the point of emergence to the adult stage. Natal dispersal may occur in the pre-reproductive (teneral) period following emergence but this study focused on breeding dispersal: dispersal undertaken after reproductive maturity away from an area of breeding activity such as the study ponds. As all breeding occurs at ponds (Dunham, 1993), and little feeding or other activity occurs adjacent to water bodies (Fried \& May, 1983; Baird \& May, 2003), males captured adjacent to the pond were assumed to be engaged in reproductive behaviour at the pond. Males at a water body spend the majority of their time perched on vegetation emerging from or adjacent to the pond, but engage in frequent territorial conflicts involving patrol flights as well as chasing, or being chased by, other males (Fried \& May, 1983). Aggressive interactions frequently involve direct contact between males including aerial battles or one male striking an already perched male (S. J. McCauley, pers. obs.). This contact may result in damage that imposes significant costs to both males (Suhonen et al., 2008).

This study was conducted at the Wantrup Wildlife Sanctuary ( $38^{\circ} 35^{\prime} 44^{\prime \prime N}$, $122^{\circ} 22^{\prime} 10^{\prime \prime} \mathrm{W}$, hereafter: WWS) in the Pope Valley, Napa Co., California (Fig. 1). The site is a protected area of oak savanna with a small set of old stock ponds created by excavation between 1956 and 1971(J. Callizo, pers. comm.) in which populations of non-native fish (Lepomis macrochirus, Micropterus salmoides, Gambusia affinis) have established. Larval $P$. longipennis were found in all the stock ponds on the WWS and adult P. longipennis were observed at all of these ponds. The adult flight season at these ponds begins in June and extends through middle to late August. The land around the WWS consists of vineyards and cattle pastures.

\section{Dispersal study}

Adult males were captured at a focal pond (Cabin Pond) on the WWS during three periods in July 2007 (period 1:9 July 2007, period 2:23 and 24 July 2007, period 3:30 and 31 July 2007). This period spans the centre of the flight season when adult populations are at their peak. Cabin Pond was chosen as the focal pond based on its central position within the reserve and its accessibility. Individuals were captured from around the pond perimeter within $3 \mathrm{~m}$ of the shore using insect nets. Males were then briefly placed in a cooler with ice- 
packs, chilling them to facilitate handling. Head width, thorax length, and forewing length, were measured on each individual using digital calipers (to $0.01 \mathrm{~mm}$ ). These aspects of morphology are fixed at the point of transition from the larval to the adult stage and do not change over the adult's lifespan. The amount of wing wear, an index positively correlated with age (Marden \& Waage, 1990), was scored on a four-point scale (from, 1 = no damage to $4=$ highly damaged). Each individual was then given a unique number written on the hindwing in black permanent ink (SharpieTm). Earlier trials with preserved wings found that these marks are readable even after 2 months of direct sun exposure. Marked individuals were allowed to warm up and then released from a common point adjacent to the pond. Resighting observations began the day after each marking period.

Between marking periods, through 3 August 2007, two observers visited four ponds on the WWS (Fig. 1) looking for marked individuals. These ponds included the original marking pond and its three nearest neighbours. One observer walked on the shore and monitored the outer margins of the pond while another observer was in the water 1-2 $\mathrm{m}$ from the shore and monitored the inner portion of the pond. Observers moved slowly around the pond and scanned for dragonflies using close-focus binoculars (Eagle Optics, Ranger SRT $6 \times 32 \mathrm{TM}$ ) to determine whether individuals spotted were marked and to read the number on marked individuals. Individuals were not recaptured, minimizing disruptions to their behaviour. Observations were conducted between 12.00 and 18.00 hours (Pacific Time), encompassing the period of peak activity in this species (Fried \& May, 1983). Ponds were visited in a sequence that minimized travel time from a starting pond that was randomly determined each day. Observers recorded the identity of resighted individuals at each pond.

All three morphological measures (head width, thorax length, forewing length) were positively correlated with each other. Therefore, a principal components analysis (PCA) was used to develop a summary measure of body size for each individual. Factor scores from this analysis were saved for each individual and these values were used in all subsequent analyses relating body size to dispersal behaviour.

Two separate AxovAs compared wing wear (score was square-root transformed) and body size from individuals marked in the three time periods. All subsequent comparisons were made between individuals marked within each period. Individuals were only captured and marked in one period but could be resighted at any time after that across the study period. However, the average 'longevity' (period across which individuals were resighted) of males in this study was 8 days with a maximum of 24 days between marking and last resight. Body size of individuals resighted and those not resighted were compared in each time period with an independent sample $t$-test. Dispersers were defined as individuals observed at a pond other than the original marking pond (Cabin Pond) while non-dispersers were those individuals resighted only at Cabin Pond. Disperser status was based on observations in this study, as an individual's history prior to capture was unknown. Therefore disperser in this context is restricted to observations of dispersal in this period rather than lifetime dispersal. An independent sample $t$-test compared the body sizes of dispersers and non-dispersers from each marking period. All $t$-tests were adjusted for non-homogeneity of variance when necessary.

In order to assess whether body size was related to how far a disperser travelled, a Spearman rank correlation was used to assess the relationship between dispersal distance (total distance travelled between ponds) and body size. This test compared only those individuals that 
dispersed, excluding individuals resighted only at the focal pond (i.e. when dispersal distance equals 0 ).

Focal observations

In July 2008 adult males were captured at the start of each week (typically just Mondays but Monday and Tuesday in the first week) at Cabin Pond using insect nets. These individuals were handled, measured, and marked in the same way as individuals captured in the dispersal study with one exception; numbers were written on both fore- and hind-wings. This facilitated reading the numbers from a fixed position during the course of a focal observation.

Observations of marked individuals were conducted on 14 days between the 3 July 2008 and 28 July 2008 at Cabin Pond and its nearest neighbour, Valley Pond. To facilitate thorough sampling of individuals at the pond, the perimeter of each pond was divided into $\sim 30 \mathrm{~m}$ sections marked with flagging. Observers slowly walked the interior perimeter of the pond searching for marked individuals, starting at the beginning of a randomly selected section. When marked individuals were spotted, focal observations began. During focal observations, the frequency of several behaviours that provide information on the individual's level of activity, aggressive interactions, and mating behaviour were recorded. These behaviours included chasing (CS), leaving the area (LA), leaving the perch (LP), moving between perches (MP), mating (MT), and being pursued (PD) (details of behaviour in Table 1). Observers also recorded the start and end time of the observation period and the pond section in which the observation occurred. Focal observations were conducted for $5 \mathrm{~min}$, or until an individual flew out of sight of the observer and remained out of sight for $1 \mathrm{~min}$. To ensure that the entire pond was searched each day, focal observations were conducted on no more than four individuals within a section during the initial circumnavigation of the pond. After all sections had been searched at least once, observers searched additional randomly selected sections and conducted focal observations within these. An average of 20 observations were made per day and this rate was consistent across the season (comparison of the number of observations per day across weeks, AxovA: F3,10=0.47, P = 0.71). Counts of the number of adult, male P. longipennis within two randomly determined sections were made four times across the study period (on 4, 10, 18, 25 July 2008) at three ponds within the study area (Cabin, Valley, and Wantrup). Observers also counted mating pairs not involving marked individuals which were seen during their focal observations. All observations were conducted between 12.00 and 17.00 (Pacific Time), the peak period of activity at the ponds.

The three morphological measures of body size were combined in a PCA, and individual factor scores saved from this analysis were used as a summary measure of body size. Spearman's correlations were used to examine the relationship between body size and the frequency (number of times behaviour observed/minutes observed) of each behaviour recorded during focal observations. For males that were observed multiple times, the mean rate of each behaviour (number of times behaviour observed/total minutes observed) was used in analyses. A general linear model (GLM) was used to compare adult male densities (number per section) across the study period and between ponds. To assess whether the variation in abundance across the study was related to the intensity of aggressive interactions at the pond, a Spearman's correlation was used to assess whether there was a relationship between the frequency of aggressive encounters [(CS + PD)/ number of individuals observed] 
and the number of males observed on a given day. All analyses were conducted in SPSS, version 15.

\section{Results}

\section{Dispersal study}

A total of 266 male P. longipennis were marked at Cabin Pond and 127 (48\%) were resighted at one or more study ponds during 85.7 person-hours of observations. Among all individuals resighted, $29 \%$ were observed to have dispersed to other ponds. Dispersal rates varied across the three marking periods from nearly a quarter to one-third of individuals resighted (period 1:34\%, period 2:23\%, period 3:33\%). The average distance travelled by dispersers was $0.43 \mathrm{~km}$ (range: $0.32-1.91 \mathrm{~km}$ ) and these movements included individuals that moved between multiple ponds. Four different dispersal trajectories were observed all starting from Cabin Pond, dispersal to Valley Pond, dispersal to Valley Pond followed by a return to Cabin Pond, dispersal to Lake Wantrup, and one individual that dispersed to Lake Wantrup and then to Upper Lake (Fig. 2).

Head width, thorax length, and forewing length all loaded strongly and positively $(0.91-$ 0.92 on an unrotated axis) on a single principal component that explained $83.4 \%$ of the variation in the data. Body size, measured as the individual's score from the PCA, generally declined across the season and was greater in the first marking period than in the latter two periods which did not differ from each other $(F 2,263=8.75, P<0.001$; Fig. 3). Mean wing wear did not differ in the three marking periods $(F 2,263=2.87, P=0.06$, mean wing wear in periods 1 and $2=1.4$, period $3=1.2$ ) nor was wing wear correlated with wing length (Pearson's $r=0.029, P=0.643$ ). Observations of newly emerged adults and exuviae (larval exoskeletons left on shoreline plants at emergence into the adult phase) throughout the study period confirm that individuals from the larval population at this pond were entering the adult population throughout the study, and the similarity in wing wear indicates that individuals in the three marking periods were of similar ages. The number of marked individuals observed at Cabin Pond did not differ between weeks of the study (GLM: F2,7 = 2.63, $P=0.141)$.

There was no difference in body size between individuals that were resighted and those which were not in any of the three marking periods (period 1: $t=-1.22$, d.f. $=117, P=0.22$; period 2: $t=-0.71$, d.f. $=75, P=0.48$; period 3: $t=1.03$, d.f. $=69, P=0.31$; Fig. 4). Among individuals marked in the first period, dispersers were smaller than non-dispersers $(t=2.78$, d.f. $=33, P=0.009$; Fig. 5). Dispersers and nondispersers from the later two marking periods did not differ in body size (period 2: $t=0.52$, d.f. $=51, P=0.6$; period 3: $t=-0.62$, d.f. $=37$, $P=0.54$; Fig. 5). Among dispersers there was no significant correlation between distance travelled and body size, although there is a trend towards smaller individuals travelling farther in the first marking period of the study (period 1: $r=-0.532, n=12, P=0.075$; period 2: $r=-0.345, n=12, P=0.27$, period 3: $r=0.175, n=13, P=0.57$ ).

\section{Focal observations}

A total of 231 observations were made on 108 different males for a total of $1064 \mathrm{~min}(17.7$ h). Males did not differ in body size between capture dates (GLM: F3,104 = 2.31, $P=0.081$ ) although there was a slight decline in size across this period suggesting that the seasonality of 
this change may have shifted from the year prior. Therefore, analyses of body size and behaviour relationships combined individuals from across the study period (body size measures presented in Table 2). Males that were observed once did not differ in body size from males that were observed multiple times $(t=-0.58, P=0.57$, d.f. $=106)$ nor was there any relationship between body size and longevity within the study, calculated as the number of days between when an individual was marked and when it was last sighted (Pearson's $r=$ $0.138, P=0.153$, males. Due to this small sample size, there was no analysis of this behaviour.

\section{Discussion}

$n=108$ ). There was no difference in the density of males at the three ponds surveyed (GLM: $F 2,12=0.129, P=0.88$; mean \pm 1 SD per 30 m section: Cabin $20.63 \pm 10.6$, Valley $21.5 \pm$ 10. 1 , Wantrup $19.13 \pm 9.1$ ), density at these ponds was not affected by date (GLM: F3,12= $1.78, P=0.205)$, nor was there an interaction between pond and date (GLM: $F 6,12=1.01, P$ $=0.464)$. Focal observations were available for seven of the pond-by-day combinations in which adult male counts were made in the same afternoon as focal observations. There was no correlation between the frequency of aggressive interactions and the density of males at the pond (Spearman's rho $=0.5, n=7, P=0.253$ ). However, the daily rate of aggressive interactions did increase across the season (PD per minute: Pearson's $r=0.55, P=0.04, n=$ 14; CS per minute: Pearson's $r=0.56, P=0.039, n=14$ ). Nonetheless, aggressive interactions are context dependent, requiring at least that individuals encounter other males. Therefore, tests for the correlations of individual traits with aggressive behaviour were conducted, excluding 10 individuals that were never observed to be engaged in aggressive behaviour (as either aggressor or recipient, CS or PD respectively). Correlations with other behaviours were considered for all individuals (rates of each behaviour are presented in Table 2).

There was a positive correlation between body size and how often an individual was the aggressor in chasing behaviour (CS) (Spearman's rho $=0.26, n=98, P=0.01$ ). Body size was negatively correlated with how often individuals were the object of aggressive behaviour (PD) (Spearman's rho $=-0.324, n=98, P=0.001$ ). No other behaviours were significantly correlated with body size (LA: Spearman's rho $=-0.175, n=108, P=0.07$; LP: Spearman's rho $=0.144, n=108, P=0.138$; MP: Spearman's rho $=0.076, n=108, P=0.436$ ). Mating was observed relatively infrequently. A total of only 20 mated pairs were recorded during focal observations and of these only four pairs included marked The relative value of dispersal depends on the individual phenotype or condition, the social and environmental context, and the interaction between the external context and individual state. Consequently, individuals are expected to differ in their propensity to disperse, with dispersers having a phenotype or conditional state that either decreases the costs and risks associated with dispersal or increases its potential benefits (Ims \& Hjermann, 2001; Bowler \& Benton, 2005; Benard \& McCauley, 2008; Clobert et al., 2009). Among male P. longipennis, body size was related to social dominance; large males were more often observed to be aggressors while small males were the recipients of aggression. Body size was also related to dispersal behaviour during one part of the season, when the mean body size in the population was at its peak. In this period, dispersers were significantly smaller than males that were not observed to disperse and there was a trend in this period toward a negative relationship between body size and distance travelled among dispersers. However, as male 
body size declined across the season, resulting from a combination of smaller individuals emerging into the adult population and mortality of older males, dispersers and nondispersers were no longer distinguished by body size. These results indicate that body size affects dispersal behaviour in this system during at least some portion of the breeding season, and suggest that body size may affect both dispersal propensity and how far a disperser travels. Additionally, the seasonal pattern in these results suggests that the characteristics associated with dispersal behaviour are dependent on the social context (e.g. size of other males in the population) an individual encounters.

In focal observations, body size was related to whether individuals were the recipients of aggression or the aggressors. Body size was positively correlated with the frequency with which individuals were observed to chase other males, acting as the aggressor in disputes over territory at the pond. Additionally, the negative correlation between body size and the frequency with which individuals were pursued suggests that smaller males were more often the targets of aggressive behaviour or were less successful during aggressive encounters.

The relationship between body size and social dominance appears to be a common one in odonates and one that has important consequences for mating success (Sokolovska et al., 2000). Aggressive interactions between males are often related to territorial maintenance and those males which are unable to establish or hold a territory have much lower reproductive success than males with territories (Fincke, 1992; Plaistow \& Siva-Jothy, 1996; Irusta \& Ara'ujo, 2007). For species in which males are territorial, there is considerable evidence that large males are more successful in establishing and defending territories (Moore, 1990; Fincke, 1992; Sokolovska et al., 2000; Beck \& Pruett-Jones, 2002) or in being able to act territorially for longer periods (Koenig \& Albano, 1985). Although there are exceptions to this pattern (De Block \& Stoks, 2007), and other traits such as fat reserves can affect the outcome of territorial battles (Marden \& Waage, 1990; Plaistow \& Siva-Jothy, 1996), large males typically have an advantage in holding territories and under these conditions have higher reproductive success than small males. In this study body size was an important determinant of the outcome of aggressive interactions and small males were competitive inferiors, making them vulnerable to territorial displacements. In this context, the relationship between body size and dispersal propensity during the period of the study when male size was at its peak suggests that dispersal and competitive ability are related during this period. Smaller males are likely to be at a competitive disadvantage in the context of many large males being present, and therefore during this portion of the season dispersal appears to be a condition-dependent strategy utilized by low quality males. Whether males that dispersed later in the season were competitive inferiors is unknown. No difference in body size was found between dispersers and non-dispersers after the seasonal decline in male body size but other traits potentially related to competitive dominance (e.g. fat stores) were not measured in this study.

Previous work in odonates also found correlations between body size and dispersal behaviour (Michiels \& Dhondt, 1989, 1991; Anholt, 1990; Taylor \& Merriam, 1995; Conrad et al., 2002; McCauley, 2005; but also see: Thompson, 1991, Conrad et al., 2002). However, results in this study differ from previous work as most of the earlier studies found a positive relationship between body size and dispersal rather than the negative one found in this system. Some of these differences may be attributed to the focal species' breeding system. Michiels and Dhondt $(1989,1991)$ studied a non-territorial species in which the ability to hold territory is irrelevant to the dispersal decision. Additionally, previous studies have often 
produced contradictory patterns, in some cases finding a positive association between body size and dispersal (Anholt, 1990) while no relationship has been found in other species (Thompson, 1991). In the largest study to date on the relationship between phenotype and dispersal in odonates, Conrad et al. (2002) found a positive relationship between body size and dispersal in males of one species of damselfly but no relationship in another species examined in the same study. However, rather than concluding that the relationship between phenotype and dispersal is idiosyncratic across species, results from this study suggest that understanding the breeding system

of a species and how the social and seasonal context in which dispersal decisions are made, may provide new insights into the decision by males to leave a site where reproduction has been at least attempted and search for a new breeding habitat. In $P$. longipennis, males guard breeding territories and results from this study indicate that body size affects dominance in the aggressive interactions between males. Therefore size is likely to be an important determinant of territorial and ultimately breeding success. Consequently, the relative value of dispersal may be higher for males which are small relative to other males in the population, as it presents an opportunity to search for ponds where competitive intensity is lower, potentially decreasing the frequency to which they are subject to aggressive attacks by larger males and increasing their chances of holding a territory. This hypothesis could be tested by assessing the social context of ponds where dispersers were able to establish territories as well as the traits of males that remain 'floaters', moving between ponds and never successfully establishing territories.

Pachydiplax longipennis have a long emergence period and body size declines across the season, changing the social context in which males are making dispersal decisions. This is a common pattern in temperate zone odonates (Corbet, 1999; Fincke \& Hadrys, 2001) and changes in the competitive environment associated with this decline need to be incorporated into contrasts between individuals that adopt alternative dispersal strategies. This issue may be a general one in insects, as a decline in body size across the season is common in both terrestrial and aquatic species (Sweeney \& Vannote, 1978; Palmer, 1984; Forrest, 1987; reviewed in Rowe \& Ludwig, 1991). Given this pattern, explicitly incorporating seasonal changes in body size and social interactions into dispersal studies may provide new insights into dispersal behaviour. Intraspecific male competition has been hypothesized to be an important factor driving the differences in sex-biased dispersal patterns in birds and mammals (Greenwood, 1980). However, no clear consensus has developed on the role of social dominance in determining which males from a population should disperse. In some systems there is evidence that larger and potentially dominant males are more likely than subordinate males to disperse under some, but not all, environmental conditions (shrews: Hanski et al., 1991) or that among siblings dominant individuals disperse first (owls: Ellsworth \& Belthoff, 1999). In other systems, social subordinates are more likely to disperse than dominant individuals (beetles: Lawrence, 1987; squirrels: Wauters \& Dhondt, 1993; salmon: Nakano, 1995). A more thorough understanding of how male social status affects dispersal decisions will require focusing greater attention on the social and environmental context in which individual dispersal decisions are made, and how the value of dispersal for dominant versus subordinate males changes across these conditions (Bowler \& Benton, 2005).

Knowing the relationship between competitive dominance and dispersal is a critical one for predicting the effects of patch connectivity on population processes. The social status of dispersers can affect evolutionary and ecological processes that occur within spatially 
subdivided populations. If during at least part of the season breeding dispersal is a strategy adopted by competitively inferior males, the functional level of connection between these ponds may be overestimated based on simple dispersal rates. Across the course of this study $29 \%$ of resighted males moved between ponds in the study site, a relatively high degree of exchange between sites. However, no difference in the abundance of males was observed between ponds in the year following the dispersal study (2008), which suggests that within the area of this reserve there were no low-density sites to which competitively inferior males could move. Given the low reproductive success of males that are not able to successfully hold territories (Fincke, 1992; Plaistow \& Siva-Jothy, 1996; Irusta \& Ara'ujo, 2007), these males may be 'floaters' with little chance of breeding and contributing to the genetic and demographic connections between sites. These sites may therefore have less realized connectivity than expected based on the number of individuals that disperse between ponds. Results from this study join a growing body of literature (reviewed in Clobert et al., 2009) that find that dispersers are a distinct subset of the population. Consequently, how these individuals influence the populations they connect cannot be estimated based on the mean reproductive success of males in this population. Future work on phenotype dependent dispersal in odonates and in other taxa should consider how competitive dominance affects dispersal behaviour, and whether this is likely to result in over- or under-estimation of the genetic and demographic connections that develop between populations.

\section{Acknowledgements}

I thank the Center for Population Biology at the University of California, Davis which supported this research through a Postdoctoral Research Fellowship. I also thank Sharon Lawler and Andy Sih who provided important guidance throughout this work. I am grateful for support from Locke Rowe, Marie-Jos'ee Fortin and from the Department of Ecology and Evolutionary Biology at the University of Toronto during the preparation of this manuscript. I also thank the Napa County Land Trust, Joe Callizo, Marge Hill, Chris Hill, and Carolyn Cronmer for logistical support and access to the Wantrup Wildlife Sanctuary. A. Carleton, S. Lewis, and S. Schneider helped conduct fieldwork and J. Hammond, T. Brodin, K. Smith, and R. Gilpin helped collect adults for marking. S. Schneider drew the map in Fig. 1. This manuscript was improved by comments from S. Carroll, S. Clark, L. Conrad, J. Cote, P. Epanchin, S. Fogarty, Y.H. Law, S. Lawler, C. Liang, B. Luttbeg, J. Saltz, K. Smith, and two anonymous reviewers.

\section{References}

Anholt, B.R. (1990) Size-biased dispersal prior to breeding in a damselfly. Oecologia, 83, 385-387.

Baird, J.M. \& May, M.L. (2003) Fights at the dinner table: agonistic behavior in Pachydiplax longipennis (Odonata: Libellulidae) at feeding sites. Journal of Insect Behavior, 16, 189-216.

Beck, M.L. \& Pruett-Jones, S. (2002) Fluctuating asymmetry, sexual selection, and survivorship in male darkwinged damselflies. Ethology, 108, 779-781.

Benard, M.F. \& McCauley, S.J. (2008) Integrating across life-history stages: consequences of natal habitat effects on dispersal. American Naturalist, 171, 553-567.

Bonte, D., Travis, J.M.J., De Clercq, N., Zwertvaegher, I. \& Lens, L. (2008) Thermal conditions during juvenile development affect adult dispersal in a spider. Proceedings of the National Academy of Sciences of the United States of America, 105, 17000-17005.

Bowler, D.E. \& Benton, T.G. (2005) Causes and consequences of animal dispersal strategies: relating individual behaviour to spatial dynamics. Biological Reviews, 80, 205-225. 
Clobert, J., Danchin, E., Dhondt, A.A. \& Nichols, J.D. (2001) Dispersal. Oxford University Press, Oxford, U.K.

Clobert, J., Le Galliard, J-F., Cote, J., Meylan, S. \& Massot, M. (2009) Informed dispersal, heterogeneity in animal dispersal syndromes and the dynamics of spatially structured populations. Ecology Letters, 12, 197209.

Conrad, K.F., Willson, K.H., Whitfield, K., Harvey, I.F., Thomas, C.J. \& Sherratt, T.N. (2002) Characteristics of dispersing Ischnura elegans and Coenagrion puella (Odonata): age, sex, size, morph and ectoparasitism. Ecography, 25, 439-445.

Corbet, P.S. (1999) Dragonflies: Behavior and Ecology of Odonata. Cornell University Press, Ithaca, New York.

De Block, M. \& Stoks, R. (2007) Flight-related body morphology shapes mating success in a damselfly. Animal Behaviour, 74, 1093-1098.

Dingle, H. (2006) Animal migration: is there a common migratory syndrome? Journal of Ornithology, 147, 212-220.

Dunham, M. (1993) Changes in mass, fat content, and water content with growth in adult Pachydiplax longipennis (Odonata: Libellulidae). Canadian Journal of Zoology, 71, 1470-1474.

Ellsworth, E.A. \& Belthoff, J.R. (1999) Effects of social status on the dispersal behaviour of juvenile western screech-owls. Animal Behaviour, 57, 883-892.

Fincke, O.M. (1992) Interspecific competition for tree holes - consequences for mating systems and coexistence in neotropical damselflies. American Naturalist, 139, 80-101.

Fincke, O.M. \& Hadrys, H. (2001) Unpredictable offspring survivorship in the damselfly, Megaloprepus coerulatus, shapes parental behavior, constrains sexual selection, and challenges traditional fitness estimates. Evolution, 55, 762-772.

Forrest, T.G. (1987) Insect size tactics and developmental strategies. Oecologia, 73, 178-184.

Fried, C.S. \& May, M.L. (1983) Energy expenditure and food intake of territorial male Pachydiplax longipennis (Odonata, Libellulidae). Ecological Entomology, 8, 283-292.

Greenwood, P.J. (1980) Mating systems, philopatry and dispersal in birds and mammals. Animal Behaviour, 28, 1140-1162.

Hanski, I. (1999) Metapopulation Ecology. Oxford University Press, Oxford, U.K.

Hanski, I., Peltonen, A. \& Kaski, L. (1991) Natal dispersal and social dominance in the common shrew Sorex araneus. Oikos, 62, 48-58.

Holyoak, M., Leibold, M.A. \& Holt, R.D. (eds) (2005) Metacommunities: Spatial Dynamics and Ecological Communities. University of Chicago Press, Chicago, Illinois.

Ims, R.A. \& Hjermann, D.O. (2001) Condition dependent dispersal. Dispersal (ed. by J. Clobert, E. Danchin, A. A. Dhondt and J. D. Nichols), pp 203-216. Oxford University Press, New York, New York.

Irusta, J.B. \& Ara'ujo, A. (2007) Reproductive tactics of sexes and fitness in the dragonfly, Diastatops obscura. Journal of Insect Science, 7, available online: insectscience.org/7.24.

Johnson, C. (1962) A study of territoriality and breeding behavior in Pachydiplax longipennis Burmeister (Odonata: Libellulidae). The Southwestern Naturalist, 7, 191-197.

Koenig, W.D. \& Albano, S.S. (1985) Patterns of territoriality and mating success in the white-tailed skimmer Plathemis lydia (Odonata, Anisoptera). American Midland Naturalist, 114, 1-12.

Lawrence, W.S. (1987) Dispersal - an alternative mating tactic conditional on sex-ratio and body size. Behavioral Ecology and Sociobiology, 21, 367-373.

Marden, J.H. \& Cobb, J.R. (2004) Territorial and mating success of dragonflies that vary in muscle power output and presence of gregarine gut parasites. Animal Behaviour, 68, 857-865.

Marden, J.H. \& Waage, J.K. (1990) Escalated damselfly territorial contests are energetic wars of attrition. Animal Behaviour, 39, 954-959.

Massot, M. \& Clobert, J. (1995) Influence of maternal food availability on offspring dispersal. Behavioral Ecology and Sociobiology, 37, 413-418. 
Massot, M., Clobert, J., Lorenzon, P. \& Rossi, J.-M. (2002) Condition-dependent dispersal and ontogeny of the dispersal behaviour: an experimental approach. Journal of Animal Ecology, 71, 253-261. McCauley, S.J. (2005) Differential dispersal propensities between individuals in male Leucorrhinia intacta (Odonata: Libellulidae). International Journal of Odonatology, 8, 223-232.

Meylan, S., Belliure, J., Clobert, J. \& de Fraipont, M. (2002) Stress and body condition as prenatal and postnatal determinants of dispersal in the common lizard (Lacerta vivipara). Hormones and Behavior, 42, 319-326.

Michiels, N.K. \& Dhondt, A.A. (1989) Effects of emergence characteristics on longevity and maturation in the dragonfly Sympetrum danae (Anisoptera, Libellulidae). Hydrobiologia, 171, 149-158. Michiels, N.K. \& Dhondt, A.A. (1991) Characteristics of dispersal in sexually mature dragonflies. Ecological Entomology, 16, 449-459. Moore, A.J. (1990) The evolution of sexual dimorphism by sexual selection - the separate effects of intrasexual selection and inter-sexual selection. Evolution, 44, 315-331.

Nakano, S. (1995) Individual differences in resource use, growth and emigration under the influence of a dominance hierarchy in fluvial

red-spotted masu salmon in a natural habitat. Journal of Animal Ecology, 64, 75-84.

Needham, J.G., Westfall, M.J. \& May, M.L. (2000) Dragonflies of North America. Scientific Publishers, Gainesville, Florida.

Palmer, J.O. (1984) Environmental determinants of seasonal body size variation in the milkweed leaf beetle, Labidomera clivicollis (Kirby) (Coleoptera: Chrysomelidae). Annals of the Entomological Society of America, 77, 188-192.

Plaistow, S. \& Siva-Jothy, M.T. (1996) Energetic constraints and male mate-securing tactics in the damselfly Calopteryx splendens xanthostoma (Charpentier). Proceedings of the Royal Society B - Biological Sciences, 263, 1233-1239.

Rowe, L. \& Ludwig, D. (1991) Size and timing of metamorphosis in complex life-cycles: time constraints and variation. Ecology, 72, 413-427.

Sokolovska, N., Rowe, L. \& Johansson, F. (2000) Fitness and body size in mature odonates. Ecological Entomology, 25, 239-248.

Suhonen, J., Rantala, M.J. \& Honkavaara, J. (2008) Territoriality in odonates. Dragonflies and Damselflies: Model Organisms for Ecological and Evolutionary Research (ed. by A. C'ordoba-Aguilar), pp. 203-218. Oxford University Press, New York, New York.

Sweeney, B.W. \& Vannote, R.L. (1978) Size variation and the distribution of hemimetabolous aquatic insects: two thermal equilibrium hypotheses. Science, 200, 444-446.

Taylor, P.D. \& Merriam, G. (1995) Wing morphology of a forest damselfly is related to landscape structure. Oikos, 73, 43-48.

Thompson, D.J. (1991) Size-biased dispersal prior to breeding in a damselfly - conflicting evidence from a natural population. Oecologia, 87, 600-601.

Wauters, L. \& Dhondt, A.A. (1993) Immigration pattern and success in red squirrels. Behavioral Ecology and Sociobiology, 33, 159-167. 


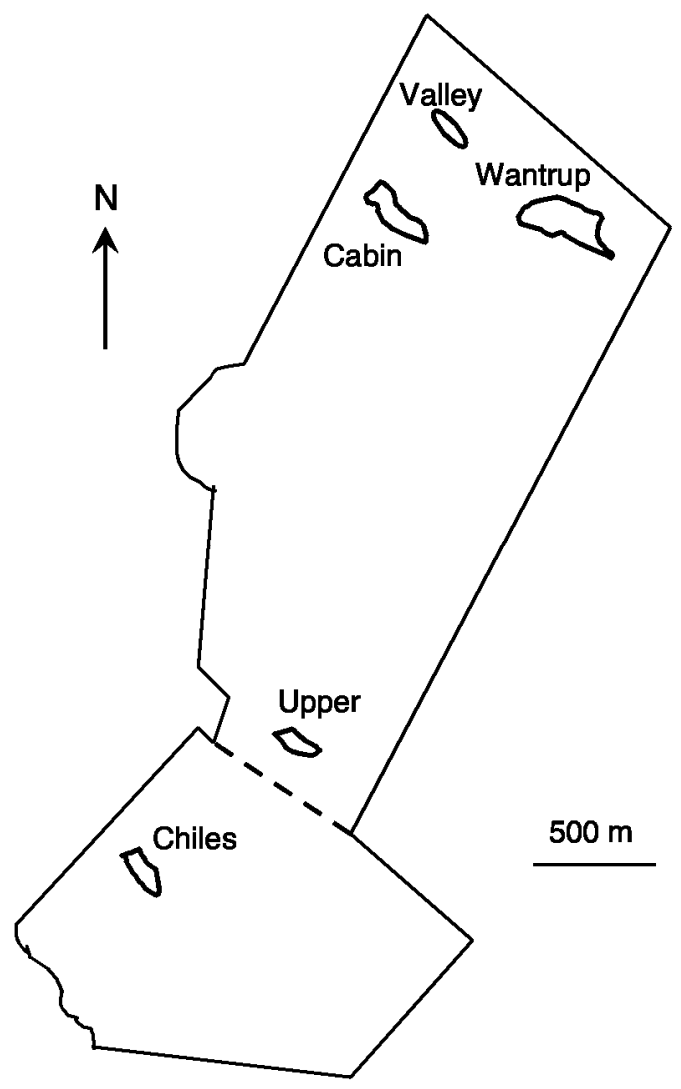

Fig. 1. Map of study sites on the Wantrup Wildlife Sanctuary with the arrangement and relative sizes of study ponds indicated. Pond names are listed below each site. Chiles Pond, south of the dotted line, was not monitored because of its isolated position on the reserve in a valley between two ridges.

Table 1. Behaviours recorded during focal observations of male Pachydiplax longipennis in July 2008.

\begin{tabular}{ll} 
Behaviour (abbreviation) & Description \\
\hline Chasing (CS) & $\begin{array}{c}\text { Individual behaves aggressively, } \\
\text { including aerial chasing, towards } \\
\text { another male } \text { P. longipennis } \\
\text { Individual leaves sight range of } \\
\text { observer and does not return within } \\
1 \text { min } \\
\text { Individual flies away from perch } \\
\text { followed by a return to same perch } \\
\text { with no stops between } \\
\text { Left perch (LP) }\end{array}$ \\
$\begin{array}{l}\text { Individual transfers between perches } \\
\text { Individual observed in copulatory } \\
\text { tandem with a female }\end{array}$ \\
Mating (MT) & $\begin{array}{c}\text { Individual is the object of aggressive } \\
\text { behaviour, including being pursued in } \\
\text { flight, by another male } P \text {. longipennis }\end{array}$ \\
&
\end{tabular}




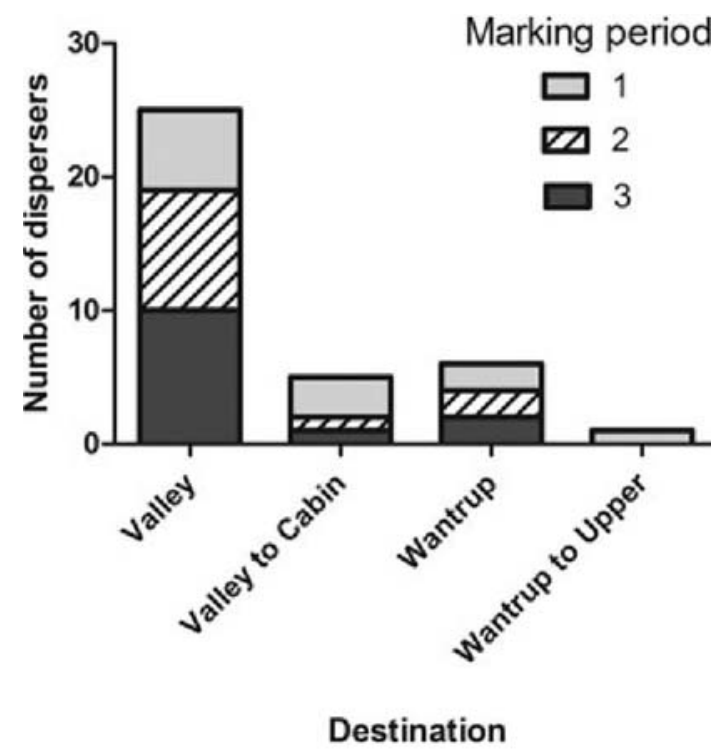

Fig. 2. The number of dispersers from each marking period that followed one of the four observed dispersal trajectories.

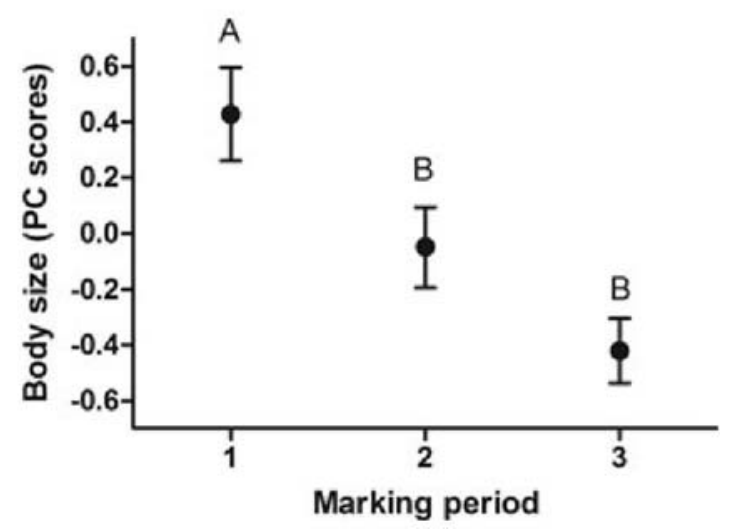

Fig. 3. Body size of male Pachydiplax longipennis captured in the three marking periods. Body sizes identified with different letters differ significantly $P<0.001$ (Tukey's post hoc test); body sizes identified by the same letter do not significantly differ. Body size measures are based on PCA scores combining measures of head width, thorax length, and forewing length. All data are means $\mathrm{f} 1 \mathrm{SE}$. 


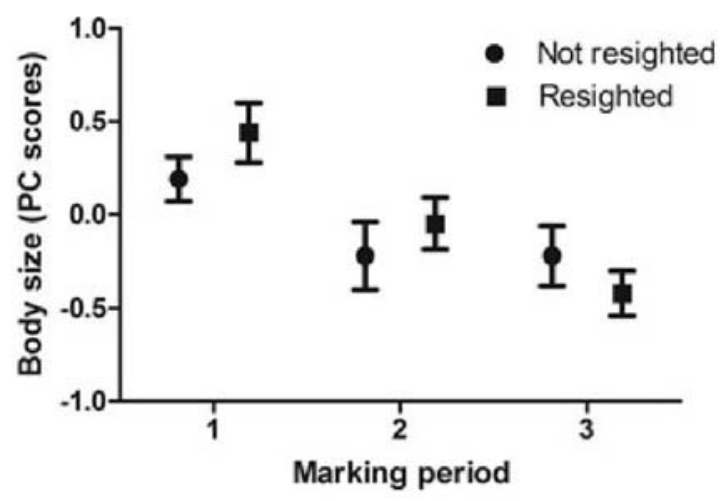

Fig. 4. Body size of individuals not resighted (circles) and those which were resighted (squares). Body size measures are based on PCA scores combining measures of head width, thorax length, and forewing length. All data are means \pm 1 SE. Sample sizes for each period are as follow: period 1: not resighted $n=83$, resighted $n=35$; period 2: not resighted $n=24$, resighted $n=58$; period 3: not resighted $n=32$, resighted $n=39$.

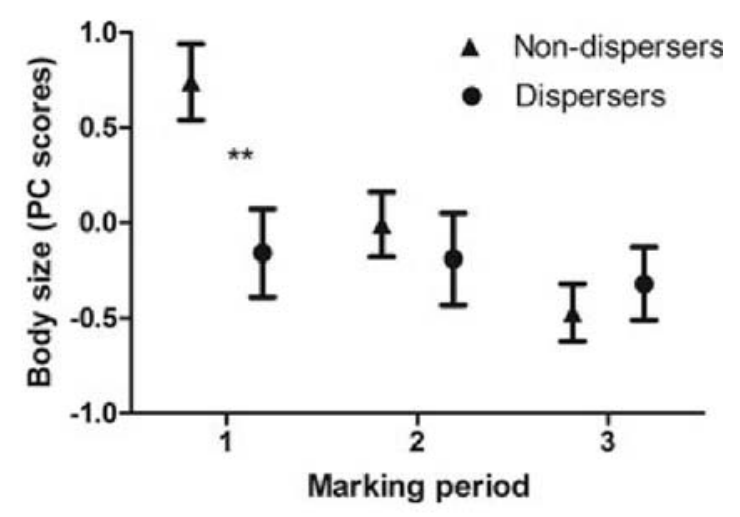

Table 2. Summary of body size measures of focal individuals $(\mathrm{mm})$ and the number of incidents of each behaviour observed per focal observation period. 


\begin{tabular}{lcc} 
Measure & Mean $\pm 1 \mathrm{SD}$ & Range (min-max) \\
\hline Head width & $5.64 \pm 0.24$ & $5.0-6.2$ \\
Thorax length & $7.53 \pm 0.58$ & $6.0-8.8$ \\
Forewing length & $28.34 \pm 1.33$ & $24.5-31.8$ \\
CS & $1.31 \pm 1.2$ & $0-8$ \\
LA & $0.39 \pm 0.54$ & $0-2$ \\
LP & $1.02 \pm 1.1$ & $0-7$ \\
MP & $1.22 \pm 1.1$ & $0-5$ \\
PD & $0.83 \pm 0.91$ & $0-5$ \\
\hline
\end{tabular}

Fig. 5. Body size of resighted males marked in three time periods including male nondispersers (triangles) and dispersers (circles). Body size measures are based on PCA scores combining measures of head width, thorax length, and forewing length. Significant differences within periods are indicated by asterisks $(* * P<0.01)$; comparisons are made within marking periods. All data are means $\pm 1 \mathrm{SE}$. Sample sizes for each period are as follows: period 1: non-dispersers $n=23$, dispersers $n=12$; period 2: non-dispersers $n=41$, dispersers $n=12$; period 3: non-dispersers $n=26$, dispersers $n=13$. 